\title{
Synthesis of IR-780 dye-conjugated abiraterone for prostate cancer imaging and therapy
}

\author{
XIAOMIN YI ${ }^{1,2^{*}}$, JINGFANG ZHANG ${ }^{3 *}$, FEI YAN ${ }^{1,2^{*}}$, ZIFAN LU $^{4}$, JIAOTI HUANG $^{5}$, CHONGXIAN PAN $^{6}$, \\ JIARUI YUAN $^{7}$, WANXIANG ZHENG ${ }^{1,2}$, KEKE ZHANG $^{1,2}$, DI WEI $^{1,2}$, WEI HE $^{3}$ and JIANLIN YUAN ${ }^{1,2}$ \\ ${ }^{1}$ Department of Urology, Xijing Hospital, Fourth Military Medical University, Xi'an, Shaanxi; ${ }^{2}$ Department of Urology, \\ PLA 105 Hospital, Hefei, Anhui; Departments of ${ }^{3}$ Chemistry, School of Pharmacy and ${ }^{4}$ Gene Technology, \\ Fourth Military Medical University, Xi'an, Shaanxi, P.R. China; ${ }^{5}$ Ronald Reagan UCLA Medical Center, \\ UCLA Medical Center, Santa Monica; ${ }^{6}$ Department of Urology, University of California at Davis Cancer Center, \\ Sacramento, CA; ${ }^{7}$ Department of Biochemistry, University of Washington, Seattle, WA, USA
}

Received May 11, 2016; Accepted June 29, 2016

DOI: $10.3892 /$ ijo.2016.3693

\begin{abstract}
Near-infrared fluorescence (NIRF) imaging is a novel imaging modality that allows for detection and real-time monitoring of various pathophysiological states. IR-780 iodide has been used as an ideal platform to construct theranostic agents for cancer imaging and therapy. Abiraterone is a 17 $\alpha$-hydroxylase/C17, 20-lyase (CYP17) inhibitor that has been approved for use in patients with prostate cancer after androgen deprivation therapy. We report the synthesis and characterization of IR-780 conjugated abiraterone for the dual purpose of prostate cancer imaging and therapy. The new compound Abi-780 retained the excellent photophysical characteristics and NIRF imaging property of IR-780 dye. Abi-780 preferentially accumulated in plasmonic organelles of prostate cancer cells but not in normal prostate epithelial cells. Dose-dependent inhibition of cultured prostate cancer cells by Abi-780 was found. Abi-780 at $20 \mu \mathrm{M}$ significantly reduced the capabilities of colony formation and migration/invasion potential as well as increasing the apoptosis rate of prostate cancer cells. NIRF imaging using Abi-780 selectively identified the tumors in mice bearing prostate cancer xenografts. Moreover, Abi-780 treatment significantly retarded the tumor
\end{abstract}

Correspondence to: Dr Wei He, Department of Chemistry, School of Pharmacy, Fourth Military Medical University, Xi'an, Shaanxi 710032, P.R. China

E-mail:weihechem@fmmu.edu.cn

Dr Jianlin Yuan, Department of Urology, Xijing Hospital, Fourth Military Medical University, 127 Changle West Road, Xi'an, Shaanxi 710032, P.R. China

E-mail: jianliny@fmmu.edu.cn

${ }^{*}$ Contributed equally

Key words: near-infrared fluorescence dye, bio-conjugation, fluorescence imaging, prostate cancer, IR-780, abiraterone growth. No severe systemic toxicity was observed in mice with daily injection of high-dose Abi-780 for one month. In conclusion, biocompatible Abi-780 is highly effective both in prostate cancer imaging and therapy. Constructing theranostic agents using the NIRF dye platform holds great promise in accurate diagnosis and targeted treatment of cancer.

\section{Introduction}

The estimated new cases and deaths of prostate cancer $(\mathrm{CaP})$ were 180,890 and 26,120, respectively, ranked first and second among all cancer types in men according to the report from American Cancer Society in 2016 (1). Since prostate cancer is an age-related disease with higher incidence in elderly men, the cumulative risk apparently shortens their life expectancy. Besides, multiple therapies available for patients with prostate cancer at advanced stages provide limited benefits (2). Both radical prostatectomy and radiation therapy are effective in curing localized low grade prostate cancer (3). Therefore, early detection and treatment remains the best strategy in prostate cancer management. PSA screen is non-specific and associated with significant false positivity and low specificity. Conventional imaging technologies are highly sensitive and specific in the diagnosis of lesions in most solid organs but prostate cancer remains an exception (4). Novel molecular imaging techniques may provide distinct advantage in solving this problem.

Near-infrared fluorescence (NIRF) imaging is a novel imaging modality for biomedical imaging application (5). Using NIRF probes with maximal absorption and emission wavelengths in the near infrared window, this technique allows for the detection of tissue function, metabolism, bio-distribution and for real-time monitoring of various pathophysiological states (6). IR-780 iodide, a lipophilic cyanine dye with peak emission at $780 \mathrm{~nm}$, has been applied for cancer imaging and therapy including photodynamic therapy (PDT) and photothermal therapy (7). This dye can accumulate selectively in cancer cells and be used to identify cancerous lesions from normal tissues, probably through the function of 
organic anion transporting peptides (OATP) and the enhanced permeability and retention effect in cancer sites $(8,9)$. The cancer targeting ability could be exploited for drug delivery to maximize therapeutic efficacy and minimizing unwanted side effects. Besides, IR-780 iodide also exhibits tumoricidal activity to drug-resistant lung cancer cells, showing the potential as an ideal platform to construct theranostic agents for cancer imaging and therapy synergistic with conventional anticancer agents (8).

Docetaxel is a first-line chemotherapy drug for castration resistant prostate cancer (10). We previously developed theranostic NIRF conjugates using docetaxel as the active components (11). This theranostic compound retains the excellent imaging ability of original NIRF dye as well as the therapeutic effects of docetaxel, displaying huge potential in prostate cancer diagnosis and therapy. Abiraterone is a 17 $\alpha$-hydroxylase/C17,20-lyase (CYP17) inhibitor that has been approved for use in patients with castration-resistant prostate cancer before or after docetaxel therapy (12-14). It is also an antagonist to the androgen receptor and an inhibitor of $3 \beta$-hydroxysteroid dehydrogenase, exerting anticancer effects (15). We report on the development of IR-780 dye-conjugated abiraterone and the testing whether the new compound may be used in prostate cancer imaging and therapy in in vitro and in vivo models. The results suggested that the novel Abi-780 conjugates can be applied as theranostic agents for both prostate cancer imaging and therapy.

\section{Materials and methods}

Chemical reagents. Cyanine dye IR-780 iodide was purchased from Sigma-Aldrich (St. Louis, MO, USA). Abiraterone, piperazine, $N, N$-dimethylformamide (DMF), succinic anhydride, $N, N$-diethylethanamin $(\mathrm{Et} 3 \mathrm{~N})$, dichloromethane, 1-(3-dimethylaminopropyl)-3-ethylcarbodiimide hydrochloride $(\mathrm{EDC} \cdot \mathrm{HCl})$ and 1-hydroxy-7-azabenzotriazole (HOAT) were purchased from ACROS (Beijing, China).

Cell lines and cell culture. Human prostate cancer cell lines PC-3, DU-145, C4-2, LNCaP and normal prostate epithelial cell line RWPE-1 were cultured in RPMI-1640 (Invitrogen Life Technologies, Carlsbad, CA, USA) supplemented with $10 \%$ fetal bovine serum (Gibco-BRL, Carlsbad, CA, USA) and penicillin $(100 \mathrm{IU} / \mathrm{ml}) /$ streptomycin $(100 \mu \mathrm{g} / \mathrm{ml})$ in a humidified incubator with $5 \% \mathrm{CO}_{2}$ at $37^{\circ} \mathrm{C}$.

Synthesis and characterization of Abi-780. Abi-780 were synthesized through three steps. Briefly, in step A, a mixture solution of IR-780 (0.677 $\mathrm{g}, 1.014 \mathrm{mmol})$ and piperazine (0.349 g, $4.056 \mathrm{mmol})$ in DMF was heated at $85^{\circ} \mathrm{C}$ under nitrogen. After completion of the reaction as indicated by thin layer chromatography, products IR-780-piperazine conjugates were purified using silica gel flash chromatography. Abiraterone $(1.0 \mathrm{~g}, 2.9 \mathrm{mmol})$, succinic anhydride $(870.61 \mathrm{mg}$, $8.7 \mathrm{mmol})$ and $N, N$-diethylethanamin $(2.41 \mathrm{ml}, 17.4 \mathrm{mmol})$ were added into dry dichloromethane $(30 \mathrm{ml})$ in another flask for step B. The crude products were subsequently purified by column chromatography and confirmed to obtain abirateronedimethyl succinate conjugates. Finally, these two purified product were mixed at a ratio of 1:1 $(0.24 \mathrm{~mol})$, then incorpo- rated with EDC.HCL (69.0 mg, $0.36 \mathrm{mmol})$, HOAT (49.0 mg, $0.36 \mathrm{mmol}$ ) and dry dichloromethane for step $\mathrm{C}$ reaction. The pure products of Abi-780 were purified by column chromatography. Infrared spectrum, nuclear magnetic resonance spectra ( ${ }^{1} \mathrm{H}$ NMR and $\left.{ }^{13} \mathrm{C} \mathrm{NMR}\right)$ and high-resolution mass spectra (HRMS) were used for structural characterization. Fluorescence spectroscopy was determined by F97 profluorescence spectrophotometer (Lengguang Tech, Shanghai, China). NIR absorption spectroscopy was determined by using a Shimadzu Spectrophotometer (UV-2550; Shimadzu Corp., Kyoto, Japan). NIRF images were captured by the IVIS Lumina II imaging station (Caliper Life Sciences, Hopkinton, MA, USA).

Uptake of Abi-780 in prostate cancer cells. The cell staining procedures were described previously (6). In brief, prostate cancer cells and normal prostate epithelial cells were placed into $35-\mathrm{mm}$ glass bottom petri dish $\left(1 \times 10^{4}\right.$ cells/well, NEST, Shanghai, China) and cultured for $24 \mathrm{~h}$. Then working solutions of Abi-780 $(20 \mu \mathrm{M})$ were added for $20 \mathrm{~min}$ at $37^{\circ} \mathrm{C}$. Cells were gently washed twice using phosphate-buffered saline (PBS) and then incubated with 4',6-diamidino-2-phenyindole (DAPI) for nuclei staining at $37^{\circ} \mathrm{C}$ for $10 \mathrm{~min}$. After repeated PBS washes and 10-min fixation using 4\% paraformaldehyde (Sigma-Aldrich), cells were immediately observed by laser confocal microscopy with fixed imaging parameters (Olympus FV1000, Tokyo, Japan), using $700 \mathrm{~nm}$ as excitation wavelength and $780 \mathrm{~nm}$ as emission wavelength (9).

Subcellular localization of Abi-780 in prostate cancer cells were detected pursuant to the previously established protocols (6). Briefly, commercially available probes Mito Tracker Green FM and Lyso Tracker Green DND-26 (Molecular Probes, Camarillo, CA, USA) were utilized to track cytoplasmic mitochondria and lysosomes. Following DAPI staining, slides underwent staining using Mito Tracker $200 \mathrm{nM}$ for $30 \mathrm{~min}$ at $37^{\circ} \mathrm{C}$, or $200 \mathrm{nM} \mathrm{DND}-26$ for $60 \mathrm{~min}$ at $37^{\circ} \mathrm{C}$. After repeated PBS rinsing, cells were observed under the confocal laser microscope. Emission/excitation lights for Mito and Lyso Tracker was 490/516 and 554/576 nm, respectively. Images were merged for co-localization analysis of Abi-780.

\section{In vitro antitumor effects}

Viability assay. Cells were exposed to different concentrations of Abi-780 $(0,2.5,5,10,20,40,80$ and $160 \mu \mathrm{M})$ to determine the inhibitory effect of Abi-780 on cell proliferation using the CCK-8 assay kit (Beyotime, Beijing, China). Briefly, $100 \mu \mathrm{l}$ LNCaP, C4-2 and RWPE-1 cells were placed into 96-well plate $\left(5 \times 10^{3}\right.$ cells/well) and cultured for $12 \mathrm{~h}$. The cells were incubated with different concentrations of Abi-780 dye for another $24 \mathrm{~h}$. Then cells were washed repeatedly using $100 \mu \mathrm{l}$ fresh medium. After mixed with $10 \mu \mathrm{l} \mathrm{CCK}-8$ reagent at $37^{\circ} \mathrm{C}$ for $4 \mathrm{~h}$, the absorbance was determined using $\mathrm{xMark}^{\mathrm{TM}}$ microplate absorbance spectrophotometer at $450 \mathrm{~nm}$ (Bio-Rad, Hercules, CA, USA). Cell viability at different Abi-780 concentrations were calculated as percentages of OD value to that in control group without dye incubation.

Colony-formation assay. The influence of Abi-780 to the self-renewal of prostate cancer cells was determined by colony-formation assay. Cancer cells seeded in 6-well plates 
(200 cells/well) were incubated with $20 \mu \mathrm{M}$ abiraterone, IR-780 and Abi-780 for $24 \mathrm{~h}$. Then cells were washed with PBS and cultured in fresh medium. At day 10, cells were fixed with $4 \%$ paraformaldehyde and stained using $0.1 \%$ crystal violet solution (Beyotime) for $5 \mathrm{~min}$. The number of colonies (>50 cells) were counted.

Apoptosis assay by flow cytometry. Cells in a 6-well plate $\left(1 \times 10^{5}\right.$ cells/well) were incubated with $20 \mu \mathrm{M}$ abiraterone, IR-780 and Abi-780 for $24 \mathrm{~h}$. No treatment was given in control group. Cells were then harvested to detect apoptotic cells by flow cytometry (Becton-Dickinson, Franklin Lakes, NJ, USA) using the Annexin V-fluorescein isothiocyanate (FITC) and propidium iodide (PI) staining kit (Beyotime) following the manufacturer's manual. Apoptosis rate was defined as the percentage of Annexin V-positive and PI-negative cells.

Migration/Invasion assay. Cultured LNCaP and C4-2 cells in $1 \%$ FBS media were placed into the upper chambers (1x10 $/$ well) and incubated with $20 \mu \mathrm{M}$ abiraterone, IR-780 and Abi-780. No treatment was given in control group. FBS (10\%) was added into the lower chamber to form a gradient prompting cell migration. For invasion assay, Matrigel-coated inserts were used as in the upper chambers. After incubation for $24 \mathrm{~h}$, cells that migrated/invaded to the bottom of upper chamber were fixed with $4 \%$ paraformaldehyde for $10 \mathrm{~min}$ and stained with $0.1 \%$ crystal violet solution (Beyotime). The number of fixed cells was counted under Olympus DP-70 fluorescence microscope.

\section{In vivo NIRF imaging of Abi-780}

Prostate cancer xenograft model. The animal experiments were permitted by the Ethics Committee of the Fourth Military Medical University and performed in accordance with Animal Care and Use Committee Guidelines of the Fourth Military Medical University. All mice were obtained from the Experimental Animal Center of the Fourth Military Medical University. They were caged in specificpathogen-free animal house under normal light-dark cycle, free access to food and water. Human prostate cancer LNCaP cells $(100 \mu \mathrm{l})\left(1 \times 10^{7}\right.$ cells $\left./ \mathrm{ml}\right)$ mixed with BD Matrigel $^{\mathrm{TM}}$ matrix (BD Biosciences, San Jose, CA, USA) at a ratio of 1:1 were inoculated subcutaneously into 27 athymic nude mice according to the previously reported procedures (16). The mice were allocated for subsequent studies when the diameter of tumor reached $\sim 5 \mathrm{~mm}$ as measured by a caliper.

Abi-780 dye for NIRF imaging of prostate cancer. For NIRF imaging studies, Abi-780 dye were injected i.p. $(0.575 \mathrm{mg} / \mathrm{kg}$ ) into 3 tumor-bearing mice. Twenty-four hours later, the tumorbearing mice were anesthetized using $2 \%$ isoflurane in $100 \%$ oxygen with a delivery rate of $1.5 \mathrm{l} / \mathrm{min}$. NIRF images of the whole body and tissue bio-distribution were taken using the IVIS Lumina II imaging station (Caliper Life Sciences). Then subcutaneous xenografts were prepared as frozen sections and paraffin-embedded tissue sections for histological analysis. Briefly, for immediate laser confocal microscopy, frozen sections (10 $\mu \mathrm{m}$ thick) were cut from tissues embedded in OCT medium (Sakura Finetek, Torrance, CA, USA), stained by DAPI, and then observed under laser confocal microscope.
For hematoxylin and eosin (H\&E) staining, sections $(5 \mu \mathrm{m}$ thick) from paraffin-embedded tissues after H\&E staining were observed under a DP-70 microscope (Japan) by an expert pathologist (17).

In vivo antitumor assay. Twenty-four athymic nude mice bearing human prostate cancer xenografts were randomly classified into four groups each containing six mice: IR-780 group, i.p. injection of $100 \mu \mathrm{l}$ IR-780 dye (3.34 mg/kg.d); Abi group, i.p. injection of $100 \mu \mathrm{l}$ abiraterone (3.5 mg/kg.d); Abi-780 group, i.p. injection of $100 \mu \mathrm{l} \mathrm{Abi-780} \mathrm{(5.75} \mathrm{mg/kg.d);} \mathrm{control}$ group, $100 \mu \mathrm{l}$ PBS was given. Tumor size was monitored in the following four weeks. Tumor volumes were calculated by the formula: tumor volume $=\left(\right.$ length $\mathrm{x}$ width $\left.{ }^{2}\right) / 2$. The whole body NIRF signal of mice from treated groups was observed under the IVIS Lumina II Imaging Station.

Toxicity studies. Twenty-four BALB/C mice (4-6 weeks old, 20-25 g) were randomly allocated to three groups to evaluate the acute toxicity of Abi-780. Daily i.p. injection of $100 \mu \mathrm{l}$ Abi-780 dye at a dose of $0.575,5.75$ and $57.5 \mathrm{mg} / \mathrm{kg}$ to $6 \mathrm{BALB} / \mathrm{C}$ mice in each group was given for 30 days. Six mice in control group were injected with $100 \mu \mathrm{l}$ normal saline. These mice were observed and weighed daily. Thirty days later, mice were sacrificed and all tissues were retrieved for histological evaluation by H\&E staining.

Statistical analysis. Numerical data are described as mean \pm standard deviation (SD). SPSS software 16.0 (SPSS Co., Chicago, IL, USA) was used for statistical analysis. The statistical significance of data was determined by one-way ANOVA. Dunnett-t test was performed for intragroup comparisons. $\mathrm{P}<0.05$ was considered as statistically different.

\section{Results}

Synthesis and characterization of Abi-780. We developed a novel route for the chemical synthesis of Abi-780 (Fig. 1A). After final purification procedure using silica gel flash chromatography, $295 \mathrm{mg}$ dark green products Abi-780 were successfully obtained. The yielding rate was $59 \%$. Molecular weight of Abi-780 was 1149.4. The melting point was $125.6-128^{\circ} \mathrm{C}$. Chemical structure of Abi-780 conjugates was confirmed by IR, NMR and HRMS. The data were listed as following: ${ }^{1} \mathrm{H} \mathrm{NMR}\left(\mathrm{CDCl}_{3}, 400 \mathrm{MHz}\right)$ : $\delta: 8.63(1 \mathrm{H}, \mathrm{s})$, $8.47(1 \mathrm{H}, \mathrm{d}, \mathrm{J}=4.8 \mathrm{~Hz}), 7.75(1 \mathrm{H}, \mathrm{s}), 7.72(1 \mathrm{H}, \mathrm{s}), 7.66(1 \mathrm{H}, \mathrm{d}$, $\mathrm{J}=8.8 \mathrm{~Hz}), 7.36(1 \mathrm{H}, \mathrm{s}), 7.33(2 \mathrm{H}, \mathrm{d}, \mathrm{J}=4.0 \mathrm{~Hz}), 7.15(2 \mathrm{H}, \mathrm{t}$, $\mathrm{J}=7.4 \mathrm{~Hz}), 7.01(2 \mathrm{H}, \mathrm{d}, \mathrm{J}=7.6 \mathrm{~Hz}), 6.00(1 \mathrm{H}, \mathrm{s}), 5.934(1 \mathrm{H}, \mathrm{s}), 5.90$ $(1 \mathrm{H}, \mathrm{s}), 5.43-5.42(1 \mathrm{H}, \mathrm{m}), 5.30(1 \mathrm{H}, \mathrm{s}), 4.69-4.67(1 \mathrm{H}, \mathrm{m}), 3.96$ $(5 \mathrm{H}, \mathrm{t}, \mathrm{J}=7.4 \mathrm{~Hz}), 3.89(2 \mathrm{H}, \mathrm{s}), 3.81(2 \mathrm{H}, \mathrm{s}), 3.61(2 \mathrm{H}, \mathrm{s}), 2.85$ $(2 \mathrm{H}, \mathrm{t}, \mathrm{J}=5.8 \mathrm{~Hz}), 2.73(2 \mathrm{H}, \mathrm{t}, \mathrm{J}=5.8 \mathrm{~Hz}), 2.53(4 \mathrm{H}, \mathrm{t}, \mathrm{J}=6.4 \mathrm{~Hz})$, $2.41(2 \mathrm{H}, \mathrm{d}, \mathrm{J}=7.2 \mathrm{~Hz}), 2.11-2.04(4 \mathrm{H}, \mathrm{m}), 1.92-1.85\left({ }^{6} \mathrm{H}, \mathrm{m}\right)$, $1.69(12 \mathrm{H}, \mathrm{s}), 1.26(19 \mathrm{H}, \mathrm{s}), 1.09$ (6H, d, J=8.8 Hz). ${ }^{13} \mathrm{C}$ NMR $\left(\mathrm{CDCl}_{3}, 100 \mathrm{MHz}\right)$ : $\delta: 172.6 ; 171.5 ; 170.8 ; 169.8 ; 147.1 ; 142.7$; $141.7 ; 140.4 ; 140.3 ; 129.8 ; 128.5 ; 125.7 ; 124.0 ; 123.4 ; 122.1$; $109.8 ; 97.6 ; 74.1 ; 57.5 ; 50.3 ; 48.4 ; 47.4 ; 45.6 ; 38.1 ; 37.0 ; 36.9$; $35.2 ; 31.9 ; 31.5 ; 30.4 ; 29.7 ; 29.1 ; 29.0 ; 28.2 ; 27.8 ; 25.3 ; 21.7$; $20.8 ; 20.5 ; 19.3 ; 16.6 ; 11.8$. IR (KBr): 3,$425 ; 3,032 ; 2,962 ; 2,927$; 2,$854 ; 1,728 ; 1,651 ; 1,543 ; 1,504 ; 1,373 ; 1,253 ; 1,165 ; 1,095$; 1,$045 ; 1,003 ; 933 ; 798 ; 714 ; 517$. HRMS $\left(\mathrm{ESI}^{+}\right)$for $\mathrm{C}_{68} \mathrm{H}_{86} \mathrm{~N}_{5} \mathrm{O}_{3}$ : 
A

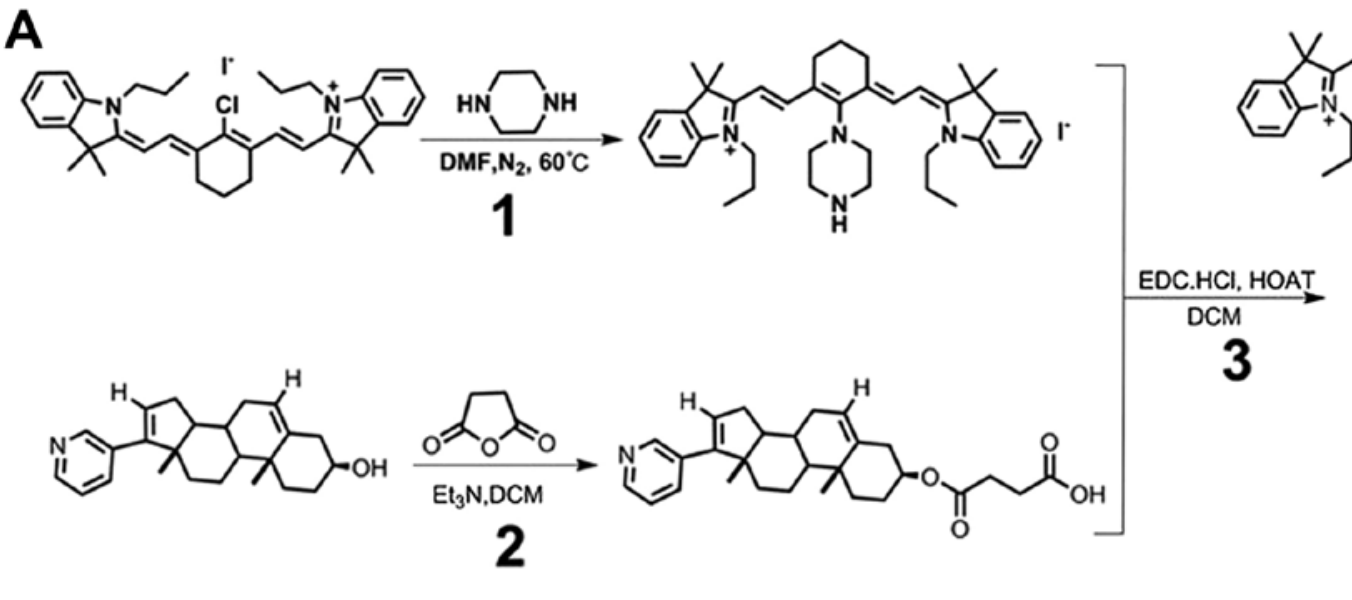
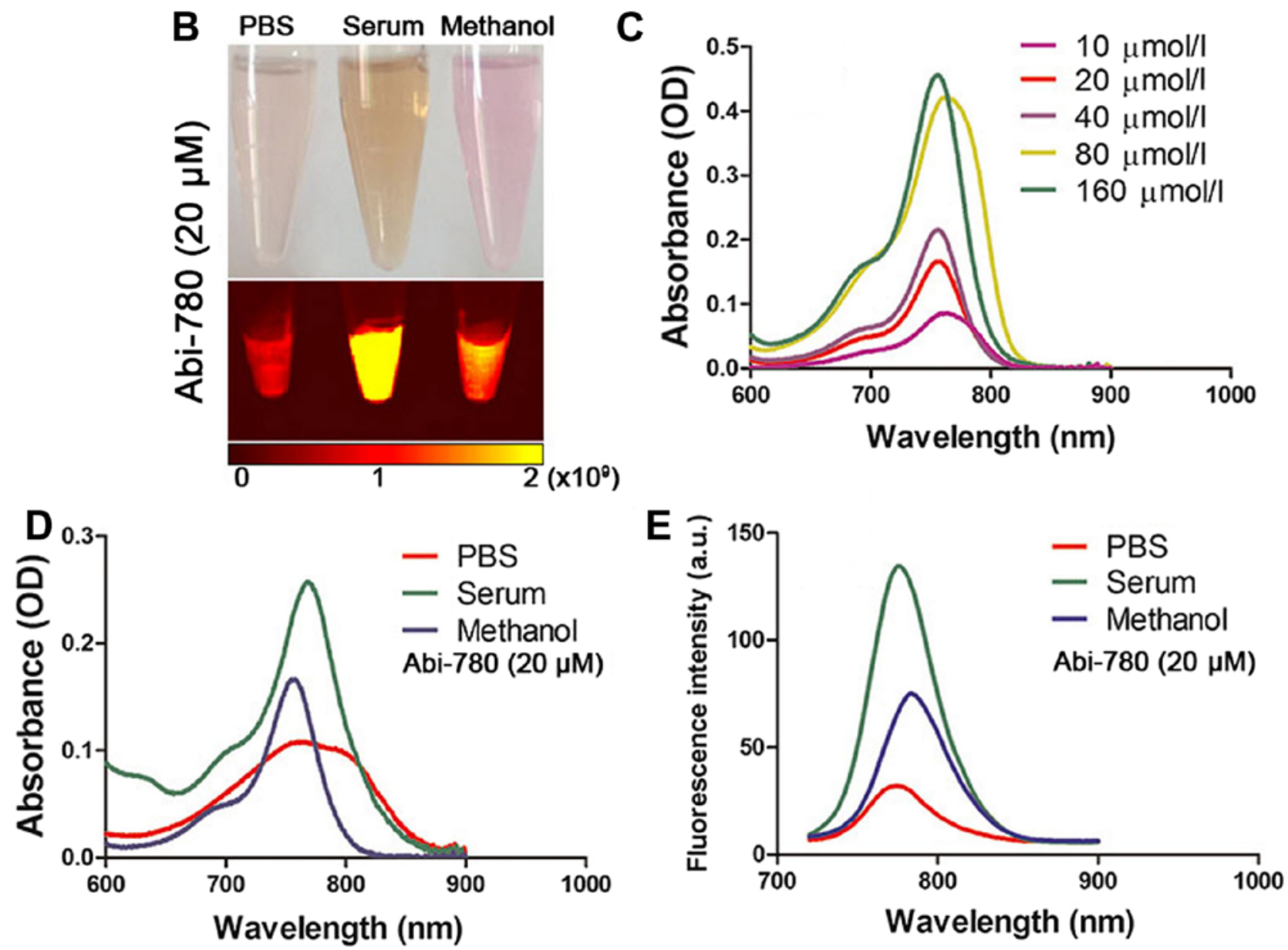

Figure 1. Chemical synthesis and characterization of Abi-780. (A) The synthesis route of Abi-780. (B) Images of Abi-780 in different solvents. (C) Absorbance of Abi-780 at different concentrations in methanol. (D) Absorbance of Abi-780 in different solvents $(20 \mu \mathrm{M})$. (E) Fluorescence intensity of Abi-780 in different solvents $(20 \mu \mathrm{M})$.

$1,020.6766$ (measured), calculated as 1,020.6731. The optical properties of Abi-780 were determined in different solvents including PBS, serum and methanol (Fig. 1B). Absorbance of Abi-780 in methanol was enhanced as the concentration increased (Fig. 1C). The absorption peak was at $760 \mathrm{~nm}$ in PBS, $768 \mathrm{~nm}$ in serum and $758 \mathrm{~nm}$ in methanol, respectively (Fig. 1D). When $700 \mathrm{~nm}$ was set as excitation wavelength, the emission peak was at $774 \mathrm{~nm}$ in PBS, $783 \mathrm{~nm}$ in serum and $776 \mathrm{~nm}$ in methanol (Fig. 1E). The emission intensity was relatively higher in serum than in PBS. The fluorescence enhancement effect and stability of Abi-780 in serum made it reliable for biomedical application.

In vitro cellular uptake study

Selective uptake and accumulation of IR-780 dye in prostate cancer cells. PC-3, DU-145, LNCaP, C4-2 and RWPE-1 were 


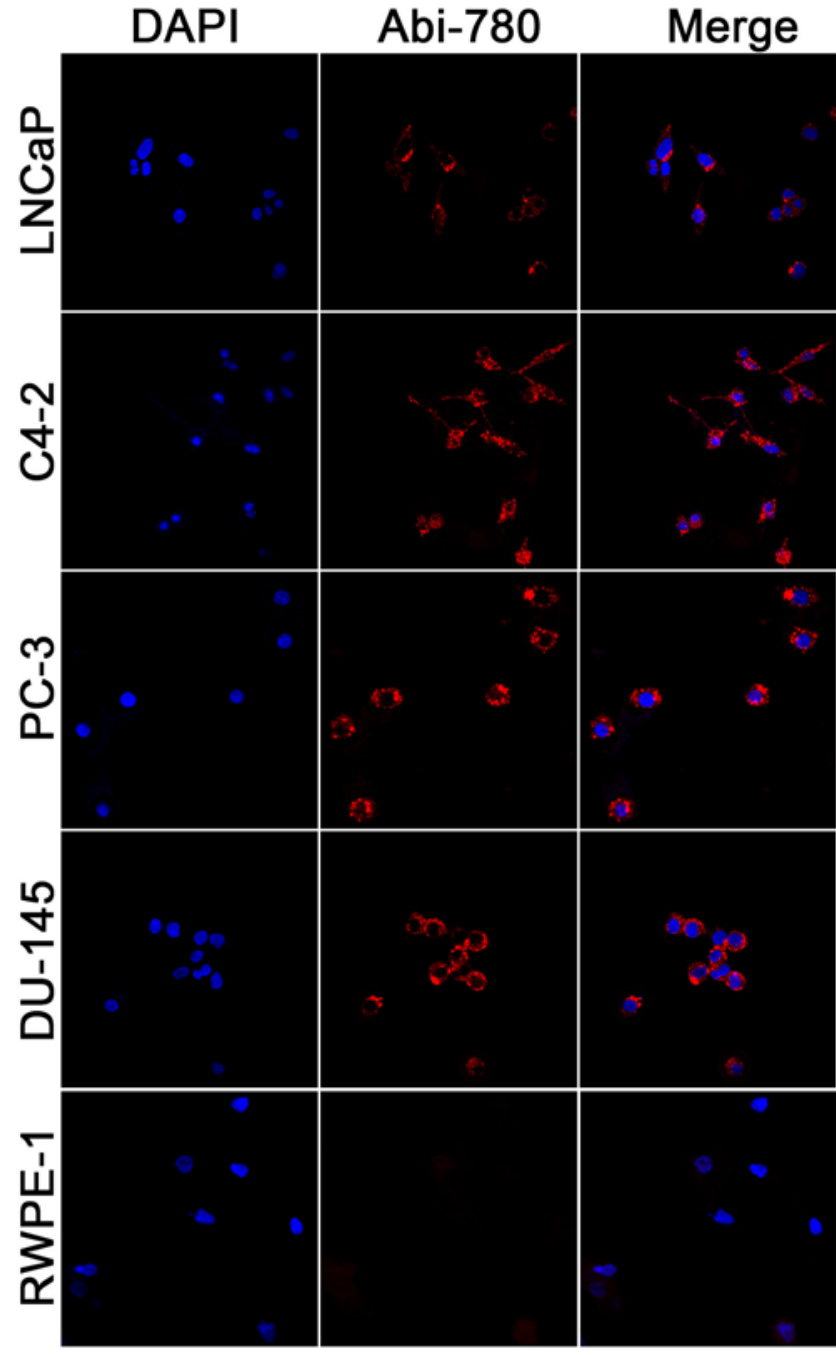

Figure 2. Preferential accumulation of Abi-780 dye in prostate cancer cells. Strong fluorescence signal was observed in prostate cancer cells, while weak signal was detected in normal prostate epithelial cells RWPE-1 (magnification, x200). DAPI was used for nuclei staining (blue). Abi-780 maintained the unique property of IR-780 for membrane transport, and was localized at lysosome and mitochondria. stained by $20 \mu \mathrm{M}$ Abi-780 to determine whether the NIRF signal varied in prostate cancer cells and normal prostate epithelial cells. Selective uptake and accumulation of NIRF dyes were found in prostate cancer cells but not in normal prostate epithelial cells (Fig. 2). These results demonstrated that the new conjugates maintained the excellent optical property of IR-780, and hence may be useful for molecularly targeted imaging.

Previous studies have documented the preferential accumulation of IR-780 dye in the mitochondria of drug-resistant lung cancer cells (18). We explored the subcellular co-localization of Abi-780 in prostate cancer cells PC-3. Cells and organelles were clearly delineated by Abi-780, Lyso-tracker and Mito-tracker dye (Fig. 3). The merged images revealed that a substantial portion of these dyes accumulated in the mitochondria and lysosomes of prostate cancer cells. These results confirmed that Abi-780 maintained the unique property of IR-780 for membrane transport, which could be utilized for selective delivery of anticancer drugs into cancer cells.

\section{In vitro antitumor effect}

Dose-dependent inhibition of cultured prostate cells by Abi-780 dye. The impact of Abi-780 on cell proliferation was evaluated in human prostate cancer cells LNCaP, C4-2 and normal human prostate epithelial cells RWPE-1. A dose-dependent inhibition on cell proliferation was revealed by MTT assay (Fig. 4A). Abi-780 at $20 \mu \mathrm{M}$ also decreased the colony-forming ability of both LNCaP and C4-2 cells in comparison with that of control group $(\mathrm{P}<0.05$, Fig. 4B). As revealed in apoptotic assays, Abi-780 significantly increased the percentage of apoptotic cells in both $\mathrm{LNCaP}$ and $\mathrm{C} 4-2$ cells compared to that of control group $(\mathrm{P}<0.05$, Fig. 4C). Furthermore, Abi-780 apparently reduced the migration and invasion potential of both LNCaP and C4-2 cells in comparison with those of control group $(\mathrm{P}<0.05, \mathrm{P}<0.05$, Fig. 4D). It was also revealed that IR-780 alone had a moderate anticancer ability on prostate cancer cells. Although abiraterone alone effectively inhibited the growth of LNCaP cells, it had limited impact on androgen

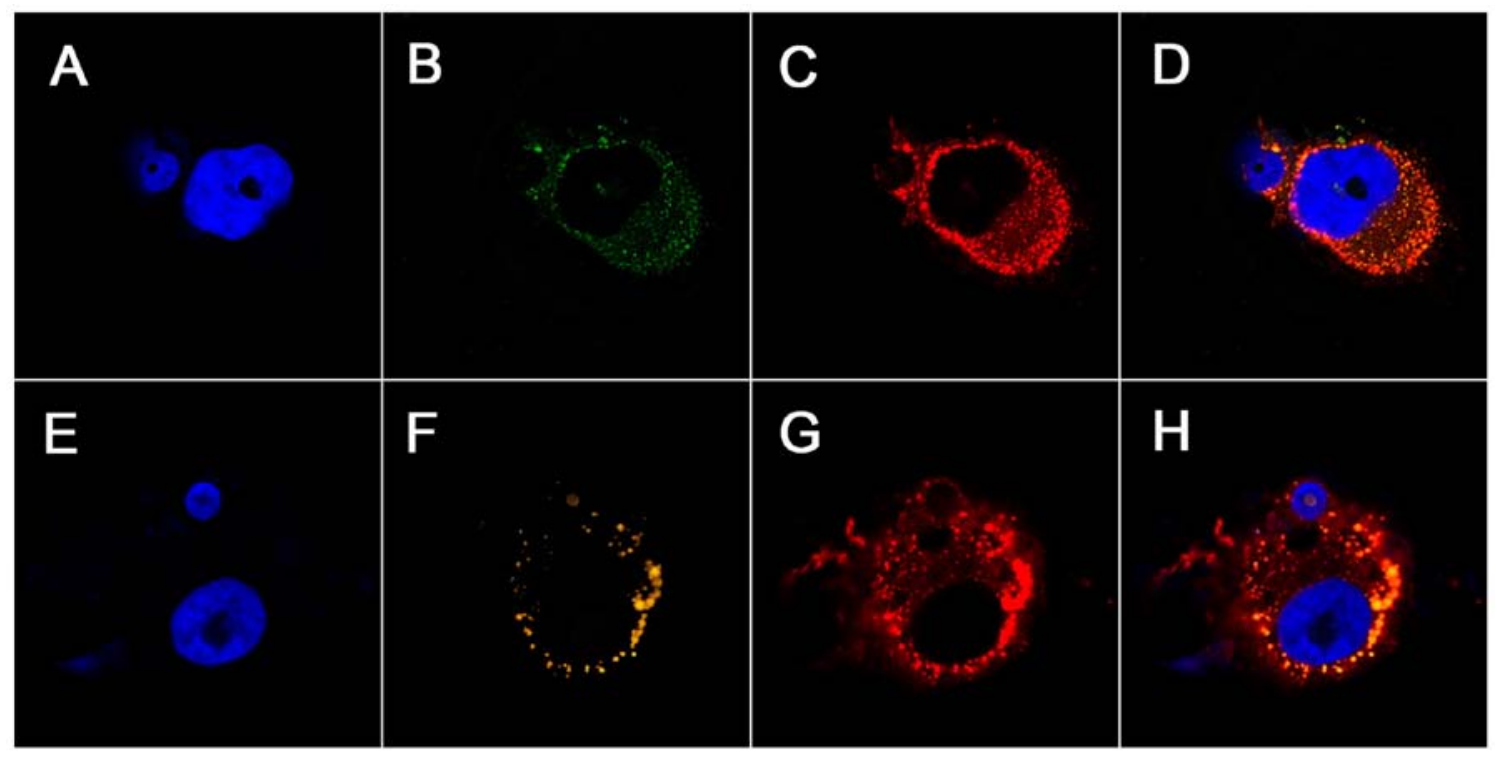

Figure 3. Subcellular co-localization analysis of Abi-780 in PC-3 cells. (A) DAPI. (B) Lyso Tracker. (C) Abi-780. (D) Merged image of A-C. (E) DAPI. (F) Mito-Tracker. (G) Abi-780. (H) Merged image of E-G (magnification, x600 using oil immersion objective). 

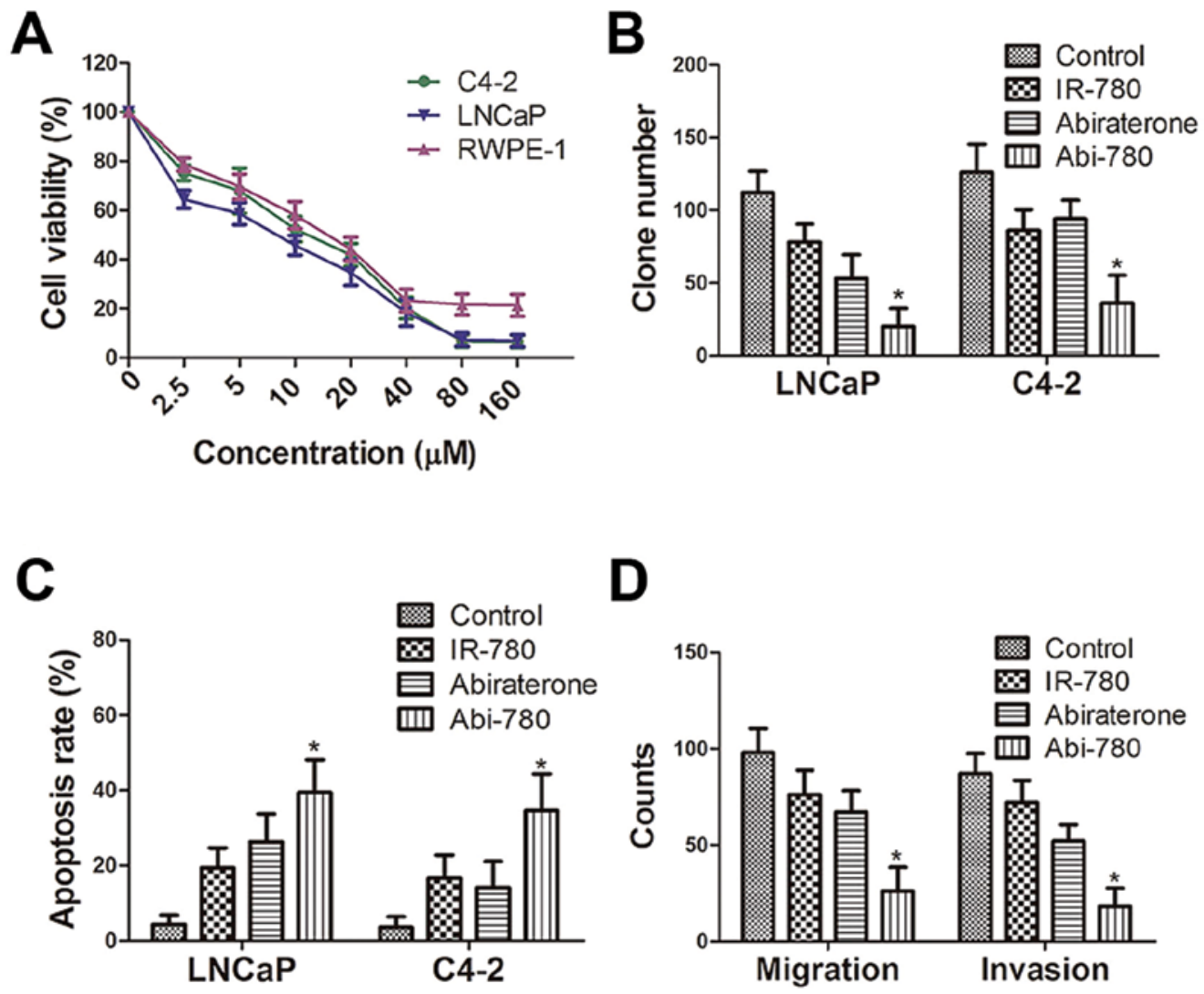

Figure 4. In vitro effect of Abi-780 on prostate cancer cells. (A) Cell viability test by MTT assay. Prostate cancer cells (PC-3 and C4-2) and normal prostate epithelial cells (RWPE-1) were incubated with Abi-780 at different concentrations $(0,2.5,5,10,20,40,80$ and $160 \mu$ mol/1) for 24 h. Dose-dependent inhibition of Abi-780 on cell proliferation was found. The $\mathrm{IC}_{50}$ of Abi-780 was 8.361, 4.174 and 5.719 $\mu \mathrm{M}$ for C4-2, LNCaP and RWPE-1 cells, respectively. (B) Colonyforming assay. (C) Apoptosis rate determined by flow cytometry. (D) Migration/invasion assay. Data are presented as mean \pm SD from three independent experiments. ${ }^{*} \mathrm{P}<0.05$.

independent C4-2cells, a metastatic subline from LNCaP cells, thus, suggesting a synergized tumor killing ability of Abi-780 in prostate cancer cells.

\section{In vivo NIRF imaging}

NIRF imaging of prostate cancer in mouse models using IR-780 dye. To validate the feasibility of using Abi-780 for live imaging, Abi-780 were i.p. injected into athymic nude mice bearing subcutaneous prostate cancer xenografts. The tumor xenografts were clearly demarcated in these mice $24 \mathrm{~h}$ after Abi-780 administration (Fig. 5A). The ex vivo bio-distribution study confirmed the selective accumulation of Abi-780 in prostate cancer tissues (Fig. 5B). The moderate signal detected in gallbladder and only a weak signal in other organs confirmed that Abi-780 was metabolized mainly through the liver. Moreover, strong NIRF signal could also be detected in frozen sections of xenografts (Fig. 5C-E). H\&E staining confirmed the existence of prostate cancer in these xenografts (Fig. 5F). The strong NIRF signal only detected in cancer tissues demonstrated the feasibility of Abi-780 for prostate cancer imaging.

In vivo antitumor effect. The in vivo antitumor effect was investigated using LNCaP tumor xenograft model. Athymic nude mice bearing prostate cancer xenografts received i.p. injection of IR-780, abiraterone or Abi-780. Tumor volumes were measured to assess the inhibitory effect on prostate cancer. The whole body NIRF signal of mice from three treated groups at the end-point confirmed inhibitory effect of Abi-780 on prostate cancer xenografts (Fig. 6A). Abi-780 showed a more pronounced tumor inhibition effect than other treatments $(\mathrm{P}<0.05)$ (Fig. $6 \mathrm{~B}$ and $\mathrm{C})$. These results confirmed the dual function of Abi-780 for cancer imaging and therapy. In addition, we applied a 10 -fold higher dose in mice to observe the toxicity of Abi-780. Mice with $\leq 57.5 \mathrm{mg} / \mathrm{kg}$ daily i.p. injection of Abi-780 experienced no death or significant weight loss. Histopathological analysis of the main organs harvested from these mice displayed no apparent abnormalities in comparison with those from normal mice (Fig. 6D).

\section{Discussion}

Radical prostatectomy is the only surgical treatment showing cancer-specific survival benefit for localized prostate cancer (3). Besides, radiation therapy, chemotherapy and androgen deprivation therapy are considered in high-risk and/or metastatic patients. However, there exist concerns about the iatrogenic trauma from invasive surgery and toxic effects from irradiation and chemotherapeutic agents. Therefore, in recent years, growing interests have been focused on developing novel multifunctional agents that can simultaneously realize cancer diagnosis and personalized therapy without severe side 

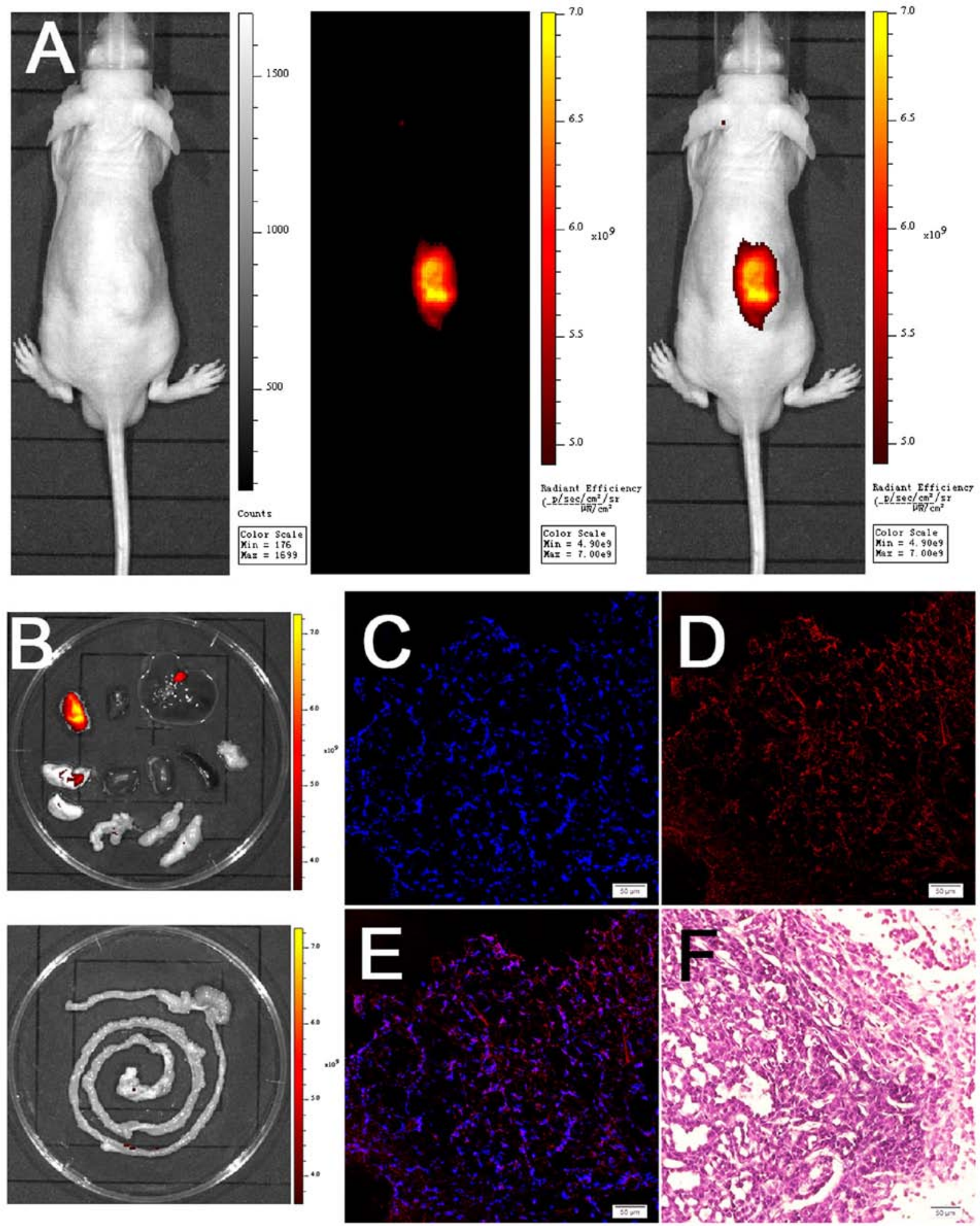

Figure 5. Near-infrared fluorescence (NIRF) imaging of subcutaneous prostate cancer xenografts using Abi-780. (A) From left to right, bright light field, NIRF field and merged image. (B) Bio-distribution studies of Abi-780 (from upper left to down right, tumor, heart, liver, lung, kindey, spleen, pancreas, bladder and seminal vesicle, testis, intestines). (C) DAPI staining of frozen sections. (D) NIRF signal from frozen sections. (E) Merged image of C and D, showing the accumulation of Abi-780 in cancer cells. (F) H\&E staining of prostate cancer xenografts (magnification, x200).

effects, offering a new concept in the management of cancer. NIRF imaging technology is a promising imaging modality that has attracted extensive attention over the last few years $(5,19)$. Using excellent NIRF probes, deep penetration of NIRF imaging is up to $10 \mathrm{~cm}$ into tissues without safety concerns about radiation exposure $(20,21)$. These NIRF probes could also be easily modified as drug delivery carriers to construct theranostic agents with potent antitumor activity. Although conventional NIRF probes are vulnerable for photobleaching and self-aggregation, IR-780 iodide displays excellent optical properties, cancer targeted imaging capability as well as remarkable tumoricidal activity in drug-resistant lung cancer 


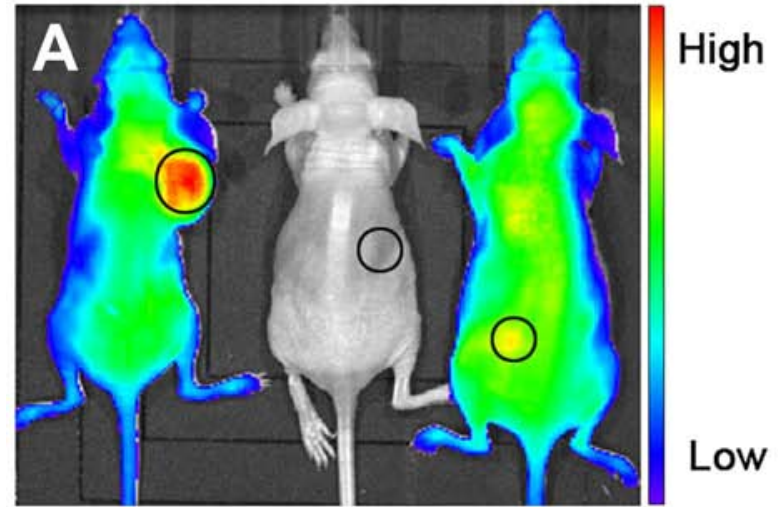

IR-780 Abiraterone Abi-780

B
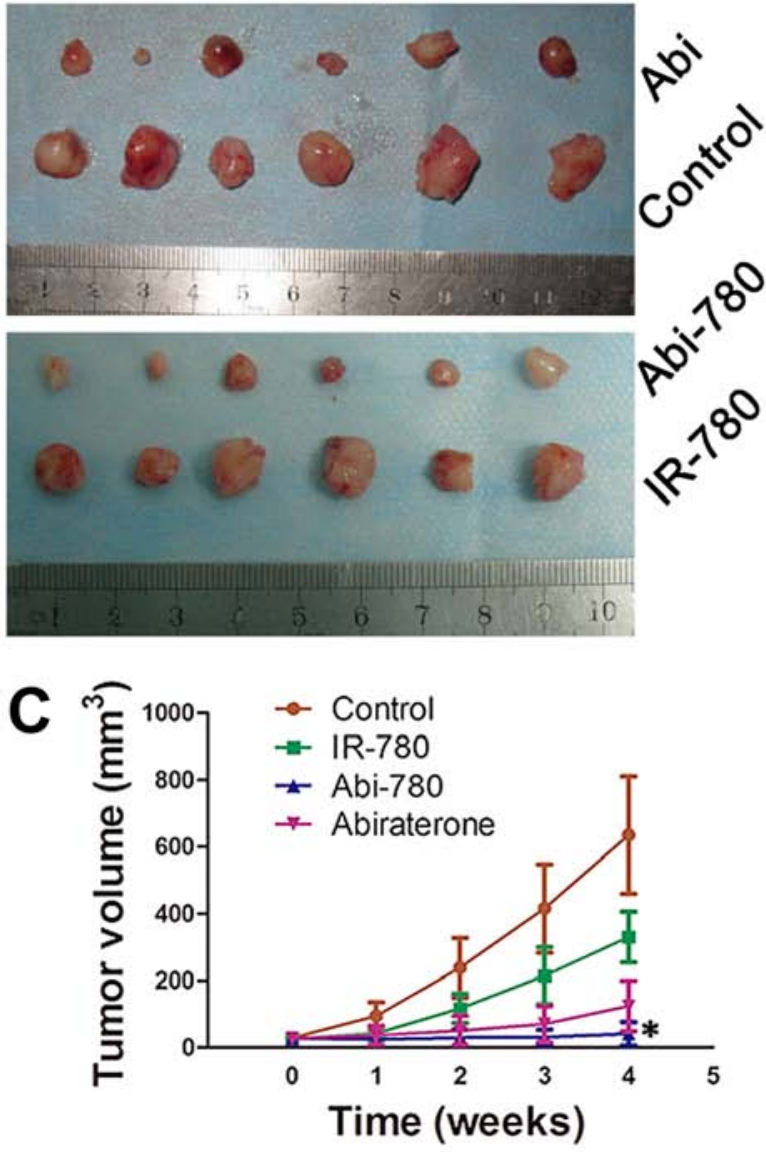

D Control

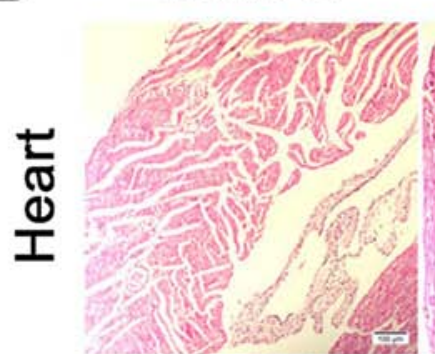

Abi-780
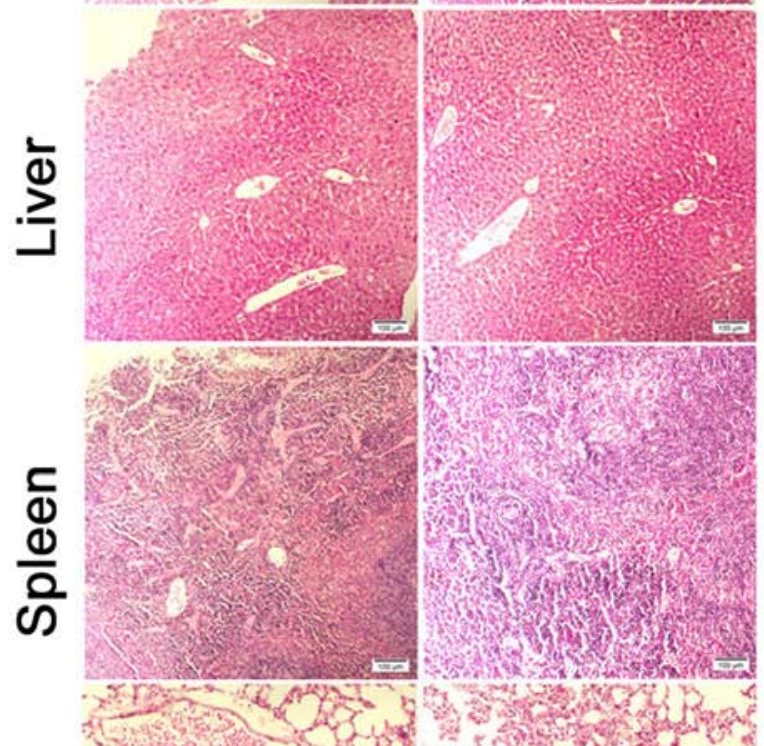

ב)

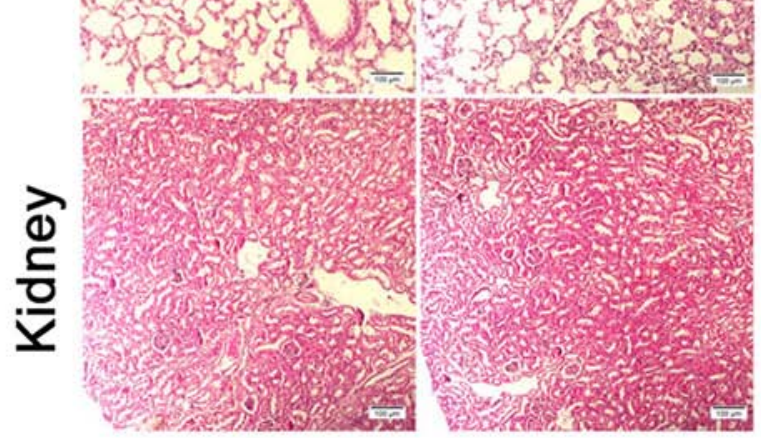

Figure 6. In vivo antitumor effect of Abi-780. (A) Real-time monitoring of therapeutic effects of treated groups. (B) Images of tumor xenografts harvested from each group at day 28. (C) The growth curve of tumor xenografts. (D) H\&E staining in toxicity studies (magnification, x200).

cells $(6,21)$. When nitrogen mustard was combined to IR-780 iodide, the new compound displayed potent antitumor effect toward cancer cells. The improved cancer targeting capability reduced severe side effects of nitrogen mustard (22).

Abiraterone is a CYP17 inhibitor that improves overall survival in prostate cancer patients with or without prior docetaxel therapy (23). Besides CYP17 inhibition, abiraterone is also an antagonist to the androgen receptor and can inhibit $3 \beta$-hydroxysteroid dehydrogenase $(15,24)$, and contribute to its antitumor effects on prostate cancer cells which express high levels of androgen receptor and synthesize their own androgens (25). However, daily use of a relatively high-dose abiraterone for prostate cancer patients is associated with increased incidence of adverse effects and toxicities $(13,26)$.

We introduced the abiraterone moiety to the structure of IR-780 to minimize the side effects of abiraterone, and in the meantime, to obtain novel theranostic agents for prostate cancer imaging and therapy. The new compound maintained the preferential accumulation of IR-780 in cancer cells, requisite for cancer targeted NIRF imaging. Abi-780 exerted a synergized tumoricidal activity against prostate cancer cells in comparison with IR-780 or abiraterone alone, showing great potential as ideal theranostic agents to realize cancer imaging and therapy simultaneously. Abiraterone is a potent inhibitor 
of androgen synthesis. Here we showed that Abi-780 could effectively inhibit clone formation and induce apoptosis of LNCaP cells, but it had little impact on androgen-independent C4-2 cells when used alone, in accordance with previous studies from another group $(27,28)$.

Another distinct advantage of theranostic agents Abi-780 is the facile real-time monitoring of therapeutic effects. Fluorescence imaging via visible light is often applied to observe the metabolism and bio-distribution of target of interest in live animals. This imaging procedure is simple to use and relatively sensitive (29). However, the depth of tissue penetration is limited by visible light. Moreover, it is impossible to realize consistent monitoring of pre-labeled targets owing to the high extinction coefficient and photo-bleaching of fluorescent dyes. Of note, NIRF dye-based multifunctional agent Abi-780 is capable of long-time in vivo monitoring (9). High specificity in prostate cancer cell imaging using Abi-780 dye might also be exploited in accurate quantification of live circulating tumor cells in prostate cancer patients (30). Theranostic agent Abi-780 makes feasible non-invasive prostate cancer imaging, therapy and real-time monitoring of therapeutic effects.

In conclusion, Abi-780 can selectively accumulate in prostate cancer cells and exert strong tumor-killing ability against prostate cancer, which could be applied as potent theranostic agents for simultaneous NIRF imaging and therapy of prostate cancer. These could also extend to sensitive and reliable noninvasive cancer imaging during surgical operations. The lack of detailed anatomical information might limit the application of Abi-780 mediated NIRF imaging, which can be solved by the multimodal imaging that combine NIRF technology and other conventional imaging modalities. NIRF technology using the armamentarium of excellent NIRF dyes will pave the way for the development of newer theranostic agents, a promising field of cancer targeted imaging and personalized therapy.

\section{Acknowledgements}

We acknowledge support from Scientifi Innovative Project of Shaanxi Province no. 2012KTCL03-03.

\section{References}

1. Siegel RL, Miller KD and Jemal A: Cancer statistics, 2016. CA Cancer J Clin 66: 7-30, 2016.

2. Cai QY, Yu P, Besch-Williford C, Smith CJ, Sieckman GL, Hoffman TJ and Ma L: Near-infrared fluorescence imaging of gastrin releasing peptide receptor targeting in prostate cancer lymph node metastases. Prostate 73: 842-854, 2013.

3. Heidenreich A, Bastian PJ, Bellmunt J, Bolla M, Joniau S, van der Kwast T, Mason M, Matveev V, Wiegel T, Zattoni F, et al; European Association of Urology: EAU guidelines on prostate cancer. part 1: Screening, diagnosis, and local treatment with curative intent-update 2013. Eur Urol 65: 124-137, 2014.

4. Osborne JR, Akhtar NH, Vallabhajosula S, Anand A, Deh K and Tagawa ST: Prostate-specific membrane antigen-based imaging. Urol Oncol 31: 144-154, 2013.

5. Yi X, Wang F, Qin W, Yang X and Yuan J: Near-infrared fluorescent probes in cancer imaging and therapy: An emerging field. Int J Nanomed 9: 1347-1365, 2014.

6. Yang X, Shi C, Tong R, Qian W, Zhau HZ, Wang R, Zhu G, Cheng J, Yang VW, Cheng T, et al: Near IR heptamethine cyanine dye-mediated cancer imaging. Clin Cancer Res 16: 2833-2844, 2010.
7. Jiang $\mathrm{C}$, Cheng $\mathrm{H}$, Yuan A, Tang $\mathrm{X}$, Wu J and Hu Y: Hydrophobic IR780 encapsulated in biodegradable human serum albumin nanoparticles for photothermal and photodynamic therapy. Acta Biomater 14: 61-69, 2015.

8. Wang Y, Liu T, Zhang E, Luo S, Tan X and Shi C: Preferential accumulation of the near infrared heptamethine dye IR-780 in the mitochondria of drug-resistant lung cancer cells. Biomaterials 35: 4116-4124, 2014

9. Yang X, Shao C, Wang R, Chu CY, Hu P, Master V, Osunkoya AO, Kim HL, Zhau HE and Chung LW: Optical imaging of kidney cancer with novel near infrared heptamethine carbocyanine fluorescent dyes. J Urol 189: 702-710, 2013.

10. Heidenreich A, Bastian PJ, Bellmunt J, Bolla M, Joniau S, van der Kwast T, Mason M, Matveev V, Wiegel T, Zattoni F, et al; European Association of Urology: EAU guidelines on prostate cancer. Part II: Treatment of advanced, relapsing, and castrationresistant prostate cancer. Eur Urol 65: 467-479, 2014.

11. Hahn C, Song SH, Oh CH and Berini P: Single-mode lasers and parity-time symmetry broken gratings based on active dielectricloaded long-range surface plasmon polariton waveguides. Opt Express 23: 19922-19931, 2015

12. Attard G, Reid AH and de Bono JS: Abiraterone acetate is well tolerated without concomitant use of corticosteroids. J Clin Oncol 28: e560-561; author reply e562, 2010.

13. Ryan CJ, Smith MR, Fong L, Rosenberg JE, Kantoff P, Raynaud F, Martins V, Lee G, Kheoh T, Kim J, et al: Phase I clinical trial of the CYP17 inhibitor abiraterone acetate demonstrating clinical activity in patients with castration-resistant prostate cancer who received prior ketoconazole therapy. J Clin Oncol 28: 1481-1488, 2010.

14. Attard G, Reid AH, A'Hern R, Parker C, Oommen NB, Folkerd E, Messiou C, Molife LR, Maier G, Thompson E, et al: Selective inhibition of CYP17 with abiraterone acetate is highly active in the treatment of castration-resistant prostate cancer. J Clin Oncol 27: 3742-3748, 2009.

15. Yin L and Hu Q: CYP17 inhibitors - abiraterone, C17,20-lyase inhibitors and multi-targeting agents. Nat Rev Urol 11: 32-42, 2014.

16. Wu TT, Sikes RA, Cui Q, Thalmann GN, Kao C, Murphy CF, Yang H, Zhau HE, Balian G and Chung LW: Establishing human prostate cancer cell xenografts in bone: Induction of osteoblastic reaction by prostate-specific antigen-producing tumors in athymic and SCID/bg mice using LNCaP and lineage-derived metastatic sublines. Int J Cancer 77: 887-894, 1998.

17. Yi X, Zhang G and Yuan J: Renoprotective role of fenoldopam pretreatment through hypoxia-inducible factor-1alpha and heme oxygenase- 1 expressions in rat kidney transplantation. Transplant Proc 45: 517-522, 2013.

18. Zhang C, Liu T, Su Y, Luo S, Zhu Y, Tan X, Fan S, Zhang L, Zhou Y, Cheng T, et al: A near-infrared fluorescent heptamethine indocyanine dye with preferential tumor accumulation for in vivo imaging. Biomaterials 31: 6612-6617, 2010.

19. Liu W, Peck EM, Hendzel KD and Smith BD: Sensitive structural control of macrocycle threading by a fluorescent squaraine dye flanked by polymer chains. Org Lett 17: 5268-5271, 2015 .

20. Hellebust A and Richards-Kortum R: Advances in molecular imaging: Targeted optical contrast agents for cancer diagnostics. Nanomedicine (Lond) 7: 429-445, 2012.

21. Yue C, Liu P, Zheng M, Zhao P, Wang Y, Ma Y and Cai L: IR-780 dye loaded tumor targeting theranostic nanoparticles for NIR imaging and photothermal therapy. Biomaterials 34: 6853-6861, 2013.

22. Zhang E, Luo S, Tan X and Shi C: Mechanistic study of IR-780 dye as a potential tumor targeting and drug delivery agent. Biomaterials 35: 771-778, 2014.

23. Sternberg CN, Castellano D, Daugaard G, Géczi L, Hotte SJ, Mainwaring PN, Saad F, Souza C, Tay MH, Garrido JM, et al; Abiraterone Global EAP Investigators: Abiraterone acetate for patients with metastatic castration-resistant prostate cancer progressing after chemotherapy: Final analysis of a multicentre, open-label, early-access protocol trial. Lancet Oncol 15: 1263-1268, 2014

24. Richards J, Lim AC, Hay CW, Taylor AE, Wingate A, Nowakowska K, Pezaro C, Carreira S, Goodall J, Arlt W, et al: Interactions of abiraterone, eplerenone, and prednisolone with wild-type and mutant androgen receptor: A rationale for increasing abiraterone exposure or combining with MDV3100. Cancer Res 72: 2176-2182, 2012. 
25. Antonarakis ES, Lu C, Wang H, Luber B, Nakazawa M, Roeser JC, Chen Y, Mohammad TA, Chen Y, Fedor HL, et al: AR-V7 and resistance to enzalutamide and abiraterone in prostate cancer. N Engl J Med 371: 1028-1038, 2014.

26. Matsubara N, Uemura H, Satoh T, Suzuki H, Nishiyama T, Uemura $\mathrm{H}$, Hashine $\mathrm{K}$, Imanaka $\mathrm{K}$, Ozono $\mathrm{S}$ and Akaza $\mathrm{H}$. A phase 2 trial of abiraterone acetate in Japanese men with metastatic castration-resistant prostate cancer and without prior chemotherapy (JPN-201 study). Jpn J Clin Oncol 44: 1216-1226, 2014.

27. Murga JD, Moorji SM, Han AQ, Magargal WW, DiPippo VA and Olson WC: Synergistic co-targeting of prostate-specific membrane antigen and androgen receptor in prostate cancer. Prostate 75: 242-254, 2015.
28. Kosaka T, Miyajima A, Yasumizu Y, Miyazaki Y, Kikuchi E and Oya M: Limited in vitro efficacy of CYP17A1 inhibition on human castration resistant prostate cancer. Steroids 92: 39-44, 2014.

29. Shan L: Near-infrared fluorescence 1,1-dioctadecyl-3,3,3,3-tetramethylindotricarbocyanine iodide (DiR)-labeled macrophages for cell imaging. In: Molecular Imaging and Contrast Agent Database. MICAD, Bethesda, MD, 2004

30. Shao C, Liao CP, Hu P, Chu CY, Zhang L, Bui MH, Ng CS, Josephson DY, Knudsen B, Tighiouart M, et al: Detection of live circulating tumor cells by a class of near-infrared heptamethine carbocyanine dyes in patients with localized and metastatic prostate cancer. PLoS One 9: e88967, 2014. 